\title{
A influência da dança na percepção de estruturas rítmicas monotônicas em adolescentes surdos
}

\author{
Effects of dance on perception of monotonic rhythmical stimuli in deaf \\ adolescents
}

\author{
E. Mauerberg-deCastro, R. Moraes
}

ARTIGO ORIGINAL | ORIGINAL ARTICLE

\begin{abstract}
Um programa de dança foi administrado para um grupo de surdos com o objetivo de melhorar a percepção de estruturas rítmicas monotônicas via estímulos visuais e estímulos auditivos. O nível do desenvolvimento psicomotor também foi analisado antes e depois da participação no programa. Vinte participantes surdos foram divididos em dois grupos, experimental (GE) e controle (GC). Antes e após a participação no programa de 26 semanas, os participantes foram avaliados em tarefas de estruturação rítmica adaptadas das clássicas provas de ritmo de M. Stambak. Ambas as tarefas incluíram a percepção de batidas em um tambor, visualizadas ou ouvidas por amplificação sonora. As respostas foram igualmente batidas no tambor. O período de prática com atividades de dança modificou o desempenho do grupo de surdos nas tarefas de estruturação rítmica. A taxa de acerto ao longo das estruturas, de complexidade crescente, melhorou, tanto quando apresentadas de forma visual, como de forma auditiva. O GC não alterou seu desempenho. Com relação ao status do desenvolvimento psicomotor do GE no pós-teste, a média ficou seis meses abaixo da idade limite das provas (11 anos). Um programa de dança pode alterar a percepção auditiva de surdos para estruturas rítmicas. A participação de surdos neste tipo de programa também resulta em mudanças no desenvolvimento psicomotor.
\end{abstract}

Palavras-chave: dança, surdez, percepção auditiva, ritmo

ABSTRACT

Dance activities were administered to a group of deaf adolescents via visual and auditory stimuli in order to improve their perceptions of monotonic rhythmic structures. Status of psychomotor development was also assessed before and after participation in the program. Twenty deaf adolescents (ages between 12 and 13 years) were divided into two groups, experimental (EG) and control (CG). Before and after participating in the program for 26 weeks, participants were evaluated in rhythmical tasks adapted from the classical test of M. Stambak. The tasks included the perception of drum beats, actually viewed hit movements, or heard via a sound amplifier. Psychomotor tests were administered only to the EG. The period of practice with dance activities changed the individuals' performance in the monotonic rhythmic test. Also, the success rate improved in both, visual and auditory input tasks. Individuals in the CG showed no changes in performance. For the EG, in the post-test, the status of psychomotor development was six months below the target age of the tests (i.e., 11 years). Findings suggested that dance activities can change deaf individuals' auditory perception of rhythmic structures. Participation in such a program can also positively affect psychomotor development.

Keywords: dance, deafness, auditory perception, rhythm

Submetido: 28.02.2012 | Aceite: 12.12.2012

Eliane Mauerberg-deCastro. Universidade Estadual Paulista, Rio Claro, Brasil.

Renato Moraes. Universidade de São Paulo, Ribeirão Preto, Brasil.

Endereço para correspondência: Profa. Dra. Eliane Mauerberg-deCastro, Laboratório de Ação e Percepção, Departamento de Educação Física, Universidade Estadual Paulista (UNESP), Av. 24-A, 1515, Rio Claro, SP 13506-900, Brasil.

E-mail: mauerber@rc.unesp.br 
Níveis severos de perda auditiva em idades precoces limitam a aprendizagem não só da comunicação oral através da escuta, mas de diversos processos perceptivos da audição ligados a atividades diversas, como a música e a dança. Propriedades temporais dos espectros acústicos da música regulam a diversidade das atividades motoras presentes na dança e nas atividades rítmicas expressivas, de forma geral. Tais propriedades não são processadas de forma espontânea ou natural pelo sistema auditivo do surdo. Entretanto, assim como os surdos tornam-se instrumentados para atingir níveis de comunicação complexa e sofisticada através da língua de sinais, também podem se tornar exímios dançarinos. O Gallaudet Dance Program é uma dentre as muitas companhias de dança formada por surdos pelo mundo afora que registra e promove atividades profissionais de dançarinos surdos há mais de 50 anos (Hottendorf \& Gill-Doleac, 2005).

"Os sons e os movimentos cíclicos ressoam na expressão criativa das pessoas que dançam. Ouvir ou não os sons tem menos importância do que expressar o ritmo, seja interno, coordenado com o outro, seja restrito pela técnica de uma coreografia" (Mauerberg-deCastro, 2011, p. 392).

O surdo comunica sua existência, as suas ideias e a sua cultura, através de gestos e sinais precisos da língua de sinais, mas também é capaz de dominar técnicas e estética corporal através da dança e ricas combinações de padrões rítmicos. Sua percepção de ritmo, entretanto, amplia-se através da interação entre múltiplos sistemas perceptivos, onde dicas visuais, estímulos vibrotáteis em contato direto com o corpo e sensações de esforço culminam em estruturação rítmica, seja ela expressa na fala, seja ela expressa no movimento dançado. Cada sistema sensorial tem variados níveis de eficiência e também limitações na transdução da informação temporal (Yuko, Reiki, \& Kazuo,
1999). Para o surdo, a percepção auditiva do ritmo (sons da música) é vaga e depende do resíduo auditivo e de oportunidades de treinamento.

Programas de dança e expressão para surdos são comuns em escolas e institutos educacionais que atendem crianças e adolescentes surdos (Luiz \& Araújo, 2003; Lopes \& Araújo, 2009; Mauerberg-deCastro, 1989; Pelc, 2002; Reber \& Sherrill, 1981). Da mesma forma, é comum no dia a dia encontrar surdos adolescentes e adultos exibindo preferências por estilos musicais e frequentando clubes na noite onde dançam em companhia dos amigos.

Muitos estudos relatam efeitos indiretos da participação de surdos em programas de dança como, por exemplo, melhoria em tarefas avaliando originalidade, iniciativa e pensamento crítico (Reber \& Sherrill, 1981), mudança de atitudes com relação à inclusão (Jarvis \& Iantaffi, 2006), melhoria no desempenho acadêmico, tomadas de decisão assertivas, iniciativa durante conversas, autoconsciência de estados de relaxamento e tensão (Pelc, 2002), assim como efeitos diretos em parâmetros fisiológicos (i.e., consumo máximo de oxigênio, tempo de exaustão) (Tsimaras et al., 2010).

Em menor expressão está o interesse em avaliar os efeitos da dança como um contexto de influência na percepção de ritmos sonoros. Em 1989, usando métodos psicofísicos, Mauerberg-deCastro demonstrou que um programa de dança de 12 semanas para surdos influenciava significativamente a discriminação auditiva de frequências tonais e a discriminação da duração de sons apresentados aos pares (Mauerberg-deCastro, 1989). Embora o estudo não tenha incluído um grupo controle, a estimulação auditiva em outros contextos de convivência do surdo não parece reforçar naturalmente seu interesse por sons. De fato, o treinamento auditivo sempre depende de orientação profissional. Neste programa, durante as sessões, a estimulação integrando sons (musicais e ambientais) via aérea e via vibração em tablado de madeira 
com as atividades perceptivo-motoras propiciava aos participantes surdos um espontâneo interesse pelos sons, segundo a autora. Os participantes eram encorajados a perceber e integrar o movimento dentro de sequências rítmicas de ambas as modalidades, acústica e vibrotátil.

Em programas de dança para surdos, o uso do tablado de madeira como meio de condução vibrotátil mostra uma óbvia limitação por causa do caráter intermitente de contato tátil, ou seja, a informação temporal é percebida apenas quando o indivíduo mantém-se fisicamente ligado à superfície que vibra. A área de contato com estas superfícies geralmente são os membros inferiores que, em movimento, acabam restringindo a exatidão tátil. Além disso, particularidades acústicas (como espectro tonal) raramente são processadas via vibração óssea tão eficientemente como a vibração aérea - detectada no ouvido interno.

Yuko et al. (1999) demonstraram que surdos podem eficientemente detectar o ritmo com as mãos e os pés durante atividades de dança utilizando estímulos vibrotáteis em contato com a pele. Para os autores, os surdos não aproveitam eficientemente a informação acústica via aural de estímulos musicais para detectar e acompanhar ritmos através da dança. Quando dançam, surdos parecem detectar estruturas rítmicas via visão e via estímulo vibrotátil. Neste último caso, somente se a fonte de estímulo vibrotátil estiver em contato com a pele.

A dança é um contexto que tipicamente combina estruturas rítmicas sonoras com movimentos corporais cíclicos. Uma questão importante é observar se existem possibilidades de transferência dos benefícios da percepção do ritmo, via visão, tato e audição, para tarefas acústicas em contextos dissociados da dança. Shahin (2011) afirma que o treinamento musical pode propiciar uma ligação neurofisiológica com a função percepção da fala em surdos e duros de ouvido. A percepção da fala certamente envolve habilidades de discrimi- nação do ritmo, tons, modulação da intensidade e timbre, tal como a percepção da música. Embora hemisférios cerebrais diferentes atuem no processamento dessas modalidades perceptuais, o movimento corporal como contexto rítmico pode também refletir mudanças no processamento de sinais acústicos com propriedades cíclicas, como é o caso do ritmo sonoro.

O objetivo deste estudo foi avaliar a influência de um programa de dança de 26 semanas na percepção de estruturas rítmicas com sequências monotônicas ${ }^{1}$. Sequências monotônicas não refletem padrões temporais como aqueles encontrados em ritmos musicais, daí a possibilidade de observar-se como a função perceptiva da audição amplia o seu funcionamento a partir da estimulação no programa de dança. Outro objetivo foi observar se indivíduos surdos percebem de forma similar as tarefas com estruturas rítmicas apresentadas com input auditivo e com input visual.

Um objetivo específico com o grupo experimental foi observar mudanças no desenvolvimento psicomotor como resultado da experiência no programa de dança. Existem várias evidências de atrasos no sistema postural de surdos com perdas neurossensoriais que acabam refletindo em tarefas de mobilidade (Brunt \& Broadhead, 1982; Brunt, Layne, Cook, \& Rowe, 1987; Lima, Pereira, \& Moraes, 2011; Savelsbergh \& Netelenbos, 1992). As perdas, que decorrem de comprometimento vestibular, podem ser atenuadas em seus efeitos no equilíbrio, se oportunidades de atividades psicomotoras forem incorporadas na rotina do indivíduo

\footnotetext{
${ }^{1}$ Sequências monotônicas são repetições de pulsos intervalados que podem se repetir em sequências temporais de duração crescente, mas sem acentos em seus pulsos tal como observados na métrica musical estruturada em compassos binários ou ternários, por exemplo. O som emitido por um metrônomo ou simplesmente bater palmas durante um exercício repetitivo caracteriza um ritmo monotônico. Surdos com perdas auditivas precoces geralmente exibem uma fala monotônica, pois não conseguem modular acentos tonais que compõem espectros acústicos de palavras e frases.
} 
surdo, especialmente na infância (Campos, 2003; Rine et al., 2004).

\section{MÉTODO}

\section{Amostra}

Vinte participantes surdos com diagnóstico de surdez neurossensorial bilateral, alunos do Instituto Londrinense de Educação de Surdos (ILES), Londrina, Brasil, foram voluntários neste estudo. A amostragem por conveniência foi subdividida em dois grupos com 10 participantes cada. Um grupo foi designado como experimental (GE) e outro como controle (GC). O Quadro I reúne dados sobre gênero, idade, nível de perda e diagnóstico da perda auditiva dos participantes de ambos os grupos. Todos tiveram autorização para participação fornecida pelos pais com anuência da equipe técnica do instituto. $^{2}$

\section{Procedimentos}

Intervenção: atividades de dança

O programa de dança foi administrado num período aproximado de 26 semanas, iniciando em abril e encerrando no início de novembro, com um intervalo de um mês no período de férias escolares em julho. Os encontros ocorreram duas vezes por semana com sessões com duração de uma hora e meia. O local das atividades incluiu um tablado com assoalho de madeira elevado a $30 \mathrm{~cm}$ de uma superfície de cimento, tornando oco o espaço entre o tablado e a superfície de cimento. Amplificadores foram conectados a seis caixas acústicas com potência de 200 watts cada, duas suspensas a uma altura de 1.5 metros da superfície, posicionadas no fundo da área do tablado. Quatro caixas acústicas adicionais foram posicionadas voltadas para a superfície de madeira nos cantos do

\footnotetext{
${ }^{2} \mathrm{O}$ estudo foi conduzido em 1984, período durante o qual não existia regulamentação nacional sobre comitês de ética no Brasil. Nesta época o ILES adotava integralmente o método oral de educação de surdos. Atualmente segue abordagem bilíngüe e a comunicação através da Língua Brasileira de Sinais (LIBRAS).
}

tablado.

A estrutura do programa de dança foi dividida nas seguintes atividades (ver Quadro II para detalhes do programa):

1. Movimentos de coordenação, equilíbrio e ritmo

2. Movimentos de expressão corporal utilizando recursos audiovisuais

3. Estimulação auditiva com amplificação sonora via aérea e via contato no tablado

4. Composição coreográfica e temas para dramatização

Os participantes do GC participaram normalmente das aulas de educação física da instituição durante o período de realização do experimento. Conforme programa do professor de educação física da instituição as atividades incluíam iniciação esportiva no voleibol, handebol e basquetebol. Os participantes do GE tiveram permissão para substituir as aulas de educação física pelas atividades do programa de dança.

Avaliação dos efeitos da participação no programa de intervenção

Percepção de estruturas rítmicas monotônicas (Prova de ritmo de Mira Stambak)

Ambos os grupos foram avaliados antes de iniciar o protocolo de intervenção (pré-teste) nas tarefas de percepção de estruturas rítmicas monotônicas. As estruturas rítmicas monotônicas foram baseadas na segunda, dentre as três provas de estruturação rítmica das provas de ritmo de Mira Stambak publicado em 1951 (Zazzo, 1968), posteriormente simplificado em Picq e Vayer (1985) e mais recentemente em Rosa Neto (2002). Neste estudo, adaptou-se a prova da versão original de Stambak para tarefas com input visual e input auditivo. Imediatamente ao final do período de intervenção, o pós-teste foi administrado.

A tarefa com estruturas rítmicas monotônicas incluiu pulsos emitidos em forma de batidas em um tambor cujos estímulos foram detectados visual e auditivamente (Quadro 
Quadro I.

Dados sobre gênero, idade, nível de perda e diagnóstico da perda auditiva dos participantes do GE e GC.

\begin{tabular}{|c|c|c|c|c|}
\hline Iniciais & Gênero & Idade & Nível de perda $(\mathrm{dB})^{*}$ & Diagnóstico de perda auditiva \\
\hline \multicolumn{5}{|c|}{ Grupo experimental } \\
\hline AMM & $\mathrm{F}$ & 14 & 102 & Surdez neurossensorial congênita \\
\hline $\mathrm{CMC}$ & $\mathrm{F}$ & 14 & 97 & Surdez neurossensorial adquirida \\
\hline $\mathrm{DBC}$ & $\mathrm{F}$ & 12 & 105 & Surdez neurossensorial congênita \\
\hline GOR & M & 13 & 108 & Surdez neurossensorial adquirida \\
\hline JCG & $\mathrm{F}$ & 13 & 118 & Surdez neurossensorial congênita \\
\hline MFS & $\mathrm{F}$ & 13 & 78 & Surdez neurossensorial congênita \\
\hline MIR & M & 14 & 115 & Surdez neurossensorial adquirida \\
\hline REM & $\mathrm{F}$ & 15 & 104 & Surdez neurossensorial adquirida \\
\hline SAG & $\mathrm{F}$ & 15 & 112 & Surdez neurossensorial adquirida \\
\hline VAV & M & 12 & 117 & Surdez neurossensorial adquirida \\
\hline Média & & 13,5 & 106 & \\
\hline DP & & 1,1 & 2,9 & \\
\hline \multicolumn{5}{|c|}{ Grupo controle } \\
\hline CRS & $\mathrm{F}$ & 11 & 87 & Surdez neurossensorial adquirida \\
\hline CES & M & 14 & 94 & Surdez neurossensorial adquirida \\
\hline CAS & $\mathrm{F}$ & 13 & 110 & Surdez neurossensorial adquirida \\
\hline FLV & M & 10 & 109 & Surdez neurossensorial adquirida \\
\hline GEM & $\mathrm{F}$ & 10 & 116 & Surdez neurossensorial congênita \\
\hline PSS & M & 15 & 87 & Surdez neurossensorial adquirida \\
\hline $\mathrm{RCM}$ & $\mathrm{F}$ & 13 & 115 & Surdez neurossensorial adquirida \\
\hline $\mathrm{RBN}$ & $\mathrm{F}$ & 14 & 114 & Surdez neurossensorial adquirida \\
\hline SMS & $\mathrm{F}$ & 12 & 120 & Surdez neurossensorial congênita \\
\hline SMI & M & 12 & 113 & Surdez neurossensorial congênita \\
\hline Média & & 12,4 & 107 & \\
\hline $\mathrm{DP}$ & & 1,7 & 1,7 & \\
\hline
\end{tabular}

III). O estímulo visual foi detectado através da observação das batidas no tambor feitas pelo experimentador. Neste caso, o participante permaneceu com fones de ouvido conectados a um aparelho audiométrico (marca Oticon Delta) emitindo ruído branco (um tipo de chiado, como quando um rádio está fora de sintonia). Na condição auditiva, o estímulo foi transmitido por meio do microfone do aparelho audiométrico, onde os ajustes foram feitos individualmente, desde que não excedessem 110 $\mathrm{dB}$, que não causassem dor e preservassem o conforto na escuta, conforme informado pelo participante. É importante ressaltar que, além da característica tonal grave, o volume de ondas emitido pela vibração da batida em um tambor é consideravelmente superior ao de um tom puro, como é o caso do estímulo gerado em um teste padrão de audiometria tonal. Desta forma, a informação auditiva tem melhor potencial de recepção por ativar, de forma mais complexa e generalizada, as células ciliadas distribuídas ao longo do órgão de Corti no ouvido interno. Todos os participantes surdos declararam ser capazes de detectar o som emitido no tambor via fone de ouvido (inclusive, participantes com ausência de resposta audiométrica). A resposta do participante foi emitida em outro tambor e visualmente inspecionada e avaliada segundo o critério "passa-falha" pelo experimentador. O critério de sucesso em cada estrutura rítmica baseou-se em reproduzir o número de estruturas e sua distribuição com pulsos e pausas. Uma vez explicada a tarefa, tanto por meio de expressão oral como por sinalização, duas tentativas de ensaio foram apresentadas antes de se iniciar a tarefa em si. A primeira estrutura ensaio foi: 00; seguida de $0 \quad 0$. Os intervalos curtos foram de aproximadamente $1 / 4$ de segundo e os longos de $1 / 2$ segundo.

Cada estrutura foi apresentada uma vez e, em seguida, reproduzida pelo participante. 
Quadro II

Estrutura do programa de dança.

\begin{tabular}{|c|c|c|}
\hline Etapas & Caracterização & Exemplos \\
\hline \multirow{7}{*}{$\begin{array}{l}\text { 1. Movimentos } \\
\text { de coordenação, } \\
\text { equilíbrio e } \\
\text { ritmo }\end{array}$} & Exercício de tronco & $\begin{array}{c}\text { Flexões; torções; ondulações; contração/relaxamento; alongamento; } \\
\text { piruetas ou giros em pé; ênfase é dada no controle postural em posições } \\
\text { estáticas ou com restrição ao equilíbrio. }\end{array}$ \\
\hline & $\begin{array}{l}\text { Exercícios com os } \\
\text { membros inferiores }\end{array}$ & $\begin{array}{l}\text { Flexão/extensão; posições estáticas e dinâmicas; passadas amplas, curtas, } \\
\text { de diferentes amplitudes e durações; direções: para frente; para trás; para } \\
\text { os lados; movimentos dissociados dos membros inferiores. }\end{array}$ \\
\hline & $\begin{array}{l}\text { Exercícios com os } \\
\text { membros superiores }\end{array}$ & $\begin{array}{l}\text { Ondulações; contração/relaxamento; rotações de diferentes segmentos; } \\
\text { movimentos com diferentes orientações; movimentos simétricos e assi- } \\
\text { métricos dos braços; direções: para frente; para trás; para os lados; movi- } \\
\text { mentos dissociados dos membros superiores. }\end{array}$ \\
\hline & Exercícios com a cabeça & $\begin{array}{c}\text { Direções alternadas: } \mathrm{p} / \text { frente; } \mathrm{p} / \text { trás; } \mathrm{p} / \text { lados; com rotação; } \mathrm{p} / \text { cima e p/ } \\
\text { baixo. }\end{array}$ \\
\hline & Planos de movimentos & $\begin{array}{l}\text { Alto; médio; baixo; em pé; sentado; deitado; decúbito dorsal e decúbito } \\
\text { ventral. }\end{array}$ \\
\hline & Tipos de ações & $\begin{array}{l}\text { Em repouso; andando; correndo; saltando; saltitando; rolando; empur- } \\
\text { rando; puxando; carregando; rastejando; girando. }\end{array}$ \\
\hline & Tipos de esforços & Forte; fraco; lento; rápido; suave; pesado; alternados. \\
\hline 2. Movimentos & Esquema corporal & $\begin{array}{l}\text { Reconhecimento de partes do corpo próprio e do outro; integrando } \\
\text { a linguagem oral e sinalizada com conceitos de contrastes, planos, } \\
\text { movimentos; integrando pulsos de músicas distintas com conceitos de } \\
\text { contrastes, planos, movimentos. }\end{array}$ \\
\hline
\end{tabular}

de expressão corporal utilizando recursos audiovisuais

Representando estruturação do espaço com o próprio corpo

com

Estruturação do espaço com vários corpos
O corpo "pesado"; o corpo que "cresce", o corpo "encolhe", o corpo "venta", o corpo "escorre", o corpo "soletra”, etc.

Construindo uma estátua com o corpo do outro; jogos de espelho; mitação de animais, plantas, elementos; introdução de temas para improvisação (uma floresta, um navio, uma casa, um restaurante etc.).

Audição passiva; iniciando e interrompendo um som musical; iniciando e interrompendo um som musical dentro de uma estrutura temporal pré-determinada para reconhecimento e acompanhamento com gestos.

Uso de fragmentos musicais com andamentos diversos; uso de estruturas musicais com predomínio de frequências baixas, altas, médias (usar equa-

Compasso musicais com predomínio de frequências baixas,
lizador do amplificador)

3. Estimulação

Controlar o som, reduzindo a intensidade e observar quantos alunos auditiva com amplificação sonora via aérea e via contato no tablado

Intensidade

\section{Tonalidade} conseguem ainda perceber a presença dos sons; identificar alunos intolerantes a certas intensidades;

Usando gravação de fragmentos musicais e sons diversificados, alternar sons com predominância em agudos e graves; inserir sons de diferentes instrumentos, vozes, volume de sons discrepantes, ruídos.

Reconhecer instrumentos musicais; vocalizações; associar movimentos

Memorização e reconhecimento ou temas estereotipados (ex. banda marcial, música de toureiro, música chinesa, música árabe, música de carnaval etc.). Associar com imagens (desenhadas ou de revistas).

Reprodução de sons

Usar instrumentos musicais ou feitos com sucata; vocalizar junto com fragmentos de refrãos musicais (associar fonemas cantados com a sinalização do alfabeto manual); trabalhar a respiração e destacar a diferença entre gemer e respirar e emitir palavras com sons orais.

\section{Composição coreográfica e temas para dramatização}

Introduzir coreografias construídas com temas socializados entre os alunos e introduzir os "movimentos" musicais; introduzir elementos de técnicas de danças clássicas e modernas; folclóricas e populares.
Integrando os

elementos acima 
Quadro III

Composição das estruturas rítmicas monotônicas da segunda prova do teste de ritmo de Mira Stambak (Zazzo, 1968).

\begin{tabular}{|c|c|c|c|c|c|}
\hline Estrutura & Composição & $\begin{array}{l}\text { Número de } \\
\text { pulsos }\end{array}$ & $\begin{array}{c}\text { Número de } \\
\text { pausas curtas/ } \\
\text { longas }\end{array}$ & $\begin{array}{c}\text { Total de } \\
\text { elementos } \\
\text { (pulsos e pausas) }\end{array}$ & $\begin{array}{c}\text { Número de } \\
\text { conjuntos }\end{array}$ \\
\hline 1 & 000 & 3 & $2 / 0$ & 5 & 1 \\
\hline 2 & $00 \quad 00$ & 4 & $2 / 1$ & 7 & 2 \\
\hline 3 & 000 & 4 & $1 / 1$ & 6 & 2 \\
\hline 4 & $\begin{array}{lll}0 & 0 & 0 \\
\end{array}$ & 3 & $0 / 2$ & 5 & 1 \\
\hline 5 & 0000 & 4 & $3 / 0$ & 7 & 1 \\
\hline 6 & 0000 & 4 & $2 / 1$ & 7 & 2 \\
\hline 7 & $\begin{array}{lll}00 & 0 & 0 \\
\end{array}$ & 4 & $1 / 2$ & 7 & 2 \\
\hline 8 & $00 \quad 00 \quad 00$ & 6 & $3 / 2$ & 11 & 3 \\
\hline 9 & $00 \quad 000$ & 5 & $3 / 1$ & 9 & 2 \\
\hline 10 & $\begin{array}{llll}0 & 0 & 0 & 0 \\
\end{array}$ & 4 & $0 / 3$ & 7 & 1 \\
\hline 11 & $\begin{array}{ll}0 & 0000 \\
\end{array}$ & 5 & $3 / 1$ & 9 & 2 \\
\hline 12 & 00000 & 5 & $4 / 0$ & 9 & 1 \\
\hline 13 & $\begin{array}{lll}00 & 0 & 00 \\
\end{array}$ & 5 & $2 / 2$ & 9 & 3 \\
\hline 15 & $\begin{array}{llll}0 & 0 & 0 & 00 \\
\end{array}$ & 5 & $1 / 3$ & 9 & 2 \\
\hline 16 & $\begin{array}{lll}00 & 000 & 0 \\
\end{array}$ & 6 & $3 / 2$ & 11 & 3 \\
\hline 17 & $\begin{array}{lll}0 & 0000 & 00 \\
\end{array}$ & 7 & $4 / 2$ & 13 & 3 \\
\hline 18 & $\begin{array}{llll}00 & 0 & 0 & 00 \\
\end{array}$ & 6 & $2 / 3$ & 11 & 3 \\
\hline 19 & $\begin{array}{llll}000 & 0 & 00 & 0 \\
\end{array}$ & 7 & $3 / 3$ & 13 & 4 \\
\hline 20 & $\begin{array}{llll}0 & 00 & 000 & 00 \\
\end{array}$ & 8 & $4 / 3$ & 15 & 4 \\
\hline 21 & $\begin{array}{lllll}0 & 00 & 00 & 0 & 00 \\
\end{array}$ & 8 & $3 / 4$ & 15 & 4 \\
\hline
\end{tabular}

Se o participante falhava, nova demonstração era realizada. Se o erro persistia, a próxima sequência era apresentada até que todas as estruturas fossem testadas. A sequência das duas condições de tarefa sempre iniciava com a condição visual, seguida da auditiva. A cada sequência correta um ponto era atribuído, num total de 21 pontos se todas as sequências fossem corretamente reproduzidas.

\section{Provas psicomotoras}

As provas psicomotoras foram sempre administradas após a avaliação nas tarefas de estruturas rítmicas e em dias diferentes. Dada a indisponibilidade de vários participantes do GC ao final do período da pesquisa para avaliações, apenas os participantes do GE realizaram as quatro provas de Ozeretski-Guilmain compiladas na bateria psicomotora de Picq e Vayer (1985) antes e após o período de intervenção. Este fato representou uma limitação importante neste estudo.

A bateria de Picq e Vayer se divide em duas etapas do desenvolvimento psicomotor, a pequena infância (de dois a cinco anos), e a média ou grande infância (de seis a 11 anos). Neste estudo utilizou-se apenas quatro provas para a média ou grande infância. As provas incluíram tarefas designadas para idades específicas entre seis e 11 anos: coordenação dinâmica das mãos, coordenação dinâmica geral, controle postural - equilíbrio e controle segmentário. Certas provas que requeriam execução com os membros superiores ou inferiores separadamente, tiveram seis meses de idade atribuídos para o membro corporal; se o participante falhava com ambos os membros a idade atribuída era a imediatamente anterior. Se a prova era corretamente executada apenas com um dos membros (direito ou esquerdo), o participante tinha atribuída a idade anterior mais seis meses. Os participantes realizaram duas tentativas e executaram todas as provas sequencialmente, independentemente da idade cronológica. As instruções foram feitas com demonstrações e explicações através de instruções orais e sinalizadas. 
Análise de dados

Devido à característica de complexidade crescente na prova de ritmo de Mira Stambak, o total de pontos acumulados na tarefa de estruturas rítmicas monotônicas para cada tipo de estímulo processado antes e depois do programa de treinamento, foi submetido à análise estatística ANOVA para três fatores (2 testes $\mathrm{x} 2$ tipos de estímulos $\mathrm{x} 2$ grupos) com medidas repetidas nos dois primeiros fatores. Quando um efeito principal ou interação significativa foi detectado, computou-se o tamanho do efeito usando o parâmetro eta squared $(\eta 2)$. De acordo com Thalheimer e Cook (2002), um efeito de tamanho da amostra de 0.8 é alto e ideal, 0.5 é médio ou moderado, e 0.2 é baixo. Valores de correlação de Pearson e de regressão linear entre as duas tarefas de estruturação rítmica monotônica foram calculados com o objetivo de analisar a relação entre as sequências rítmicas e seus níveis progressivos de complexidade. Níveis de correlação foram computados entre as provas psicomotoras.

Como o índice psicomotor na bateria de Picq e Vayer gera uma idade psicomotora, as suas mudanças decorrentes da participação no programa de dança foram analisadas usando uma ANOVA para dois fatores (2 testes $\mathrm{x} 4$ provas psicomotoras) com medidas repetidas em todos os fatores. O nível de significância foi definido como 0,05 .

\section{RESULTADOS}

\section{O perfil de acuidade auditiva}

A Figura 1 ilustra a curva de acuidade auditiva dos participantes surdos que foi determinada através de teste de audiometria tonal. $\mathrm{Na}$ banda das frequências centrais da fala (500, 1000 e $2000 \mathrm{~Hz}$ ), dois participantes do GE foram incapazes de detectar pelo menos uma das três frequências teste no melhor ouvido (Figura 1a). No GC, o número foi de quatro participantes (Figura 1b). Cálculo de ANOVA (2 grupos $\times 2$ ouvidos $\times 7$ frequências teste) com medidas repetidas nos dois últimos fatores mostrou que os grupos não diferiam entre si quanto aos níveis de acuidade auditiva, assim como estes níveis são semelhantes entre os dois ouvidos. As frequências teste diferiam entre si $(\mathrm{F} 6,108=22.39, p \leq .0001)$, confirmando a característica de perda neurossensorial. Perdas condutivas em geral mostram apenas rebaixamento da acuidade nas diferentes frequências. A análise pos-hoc de Bonferroni mostrou que os pares que diferiam entre si $(p \leq .05)$ eram: 125 e 1000, 125 e 2000, 125 e 4000, 125 e 8000 $\mathrm{Hz} ; 250 \mathrm{~Hz}$ contra todas as demais frequências acima de $500 \mathrm{~Hz}$; e entre os pares $500 \mathrm{~Hz}$ contra todas as frequências acima de $1000 \mathrm{~Hz}$. No eixo secundário das Figuras $1 \mathrm{a}$ e 1b, respectivamente GE e GC, observa-se que o número de participantes com ausência de resposta aumenta predominantemente para as frequências acima de $2000 \mathrm{~Hz}$.
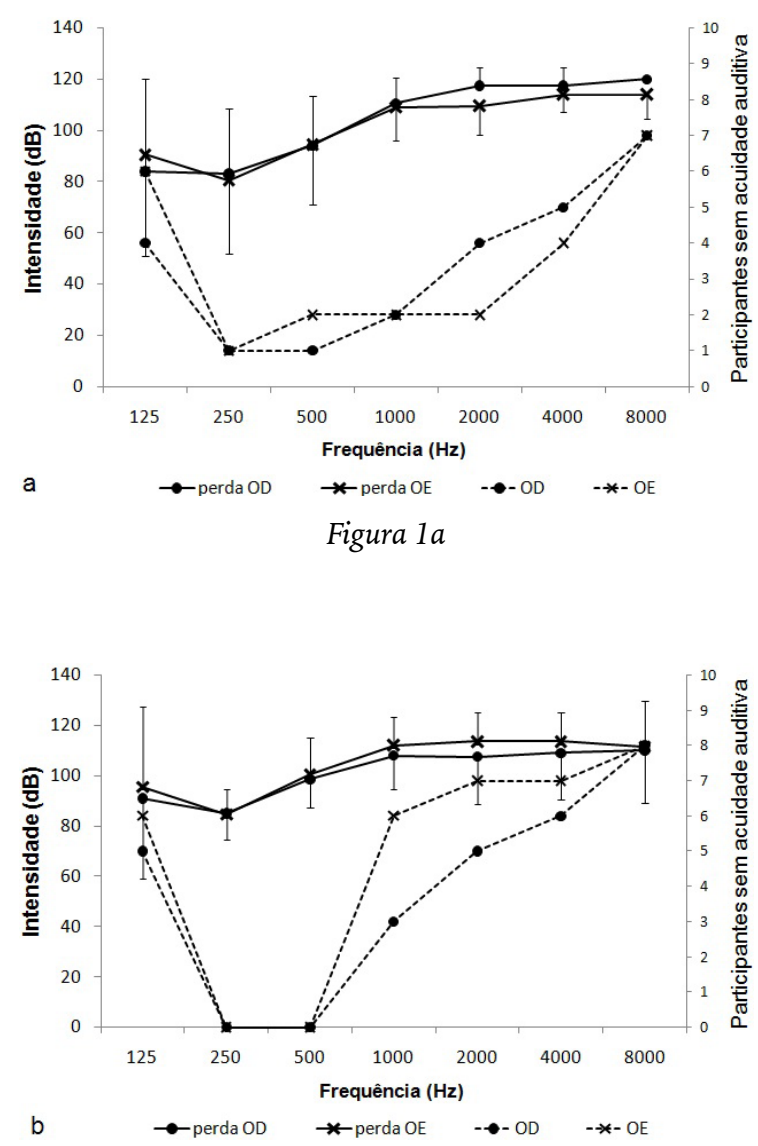

Figura $1 b$ 
Influência da dança na percepção de estruturas rítmicas

O período de 26 semanas de prática com atividades de dança modificou o desempenho do grupo de surdos nas tarefas com as estruturas rítmicas monotônicas. A pontuação pelo grupo ao longo das estruturas, de complexidade crescente, melhorou, tanto quando apresentadas de forma apenas visual, como quando apresentadas de forma auditiva. O grupo controle, submetido apenas à rotina escolar não exibiu mudanças no desempenho nessas tarefas. As Figuras 2a e 2b, respectivamente GE e GC, ilustram essas mudanças através dos valores de média e desvio-padrão para cada variável.

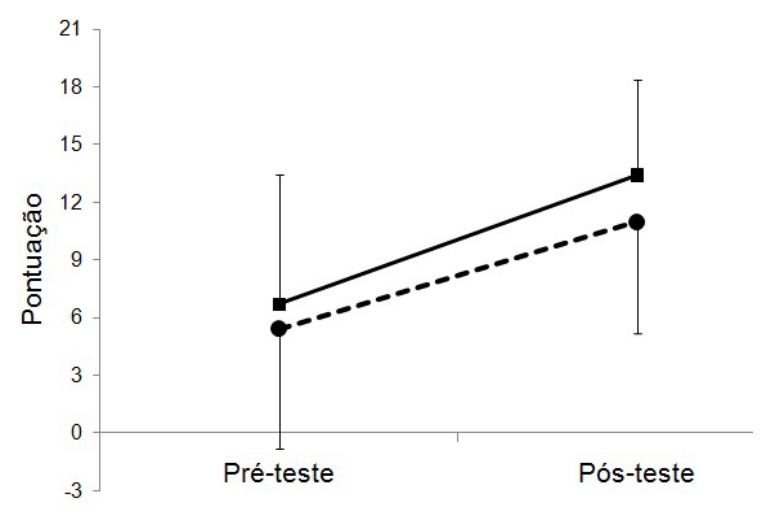

Figura $2 a$

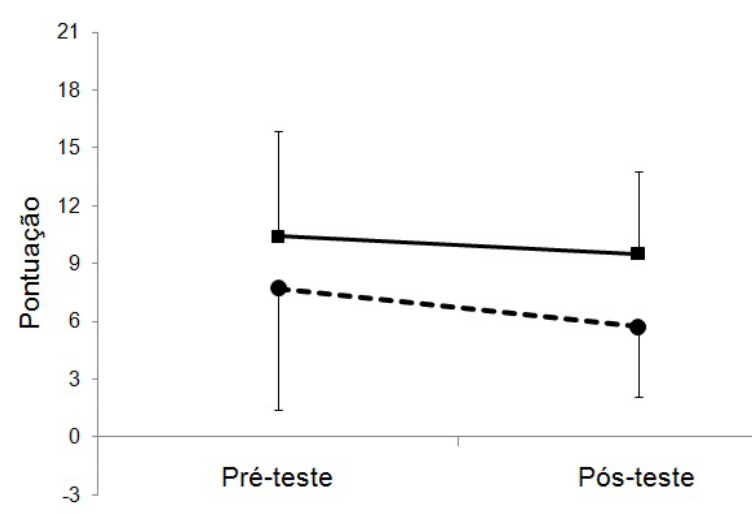

Figura $2 b$

Os resultados da ANOVA para três fatores ( 2 testes $\times 2$ tipos de estímulos $\times 2$ grupos) com medidas repetidas nos dois primeiros fatores mostraram efeito principal para teste $\left(\mathrm{F}_{1.18}=16.001 ; p \leq .0001 ; \eta 2=.471\right)$ e tipos de estímulos $\left(\mathrm{F}_{1.18}=12.542 ; p<.0002 ; \eta 2\right.$ $=.411)$, mas não para o efeito de grupo $\left(\mathrm{F}_{1.18}\right.$ $=0.128 ; p<.725)$. Porém a interação significativa entre teste e grupo $\left(\mathrm{F}_{1.18}=41.838\right.$; $p \leq .0001 ; \eta 2=.699)$ comprovou que o GE melhorou seu desempenho em ambas condições de tarefas com estruturas rítmicas monotônicas após a participação no programa de dança. O GE aumentou em $100 \%$ a média de sucesso na tarefa visual e $104 \%$ na tarefa auditiva em comparação ao GC que, por sua vez, reduziu a taxa de sucesso em $8.6 \%$ na tarefa visual e $25.9 \%$ na tarefa auditiva.

Uma análise pareada utilizando teste $\mathrm{t}$ para amostras independentes foi usada para comparar o desempenho dos grupos GE e GC entre pré- e pós-teste, separadamente nas tarefas auditiva e visual. Os resultados mostram que o GE diferiu do GC apenas no pós-teste para as tarefas com estímulos auditivos $\left(\mathrm{t}_{18}\right.$ $=2.45 ; p<.025)$. Na análise pareada entre pré- e pós-teste para o GE, ambas as tarefas mostraram uma evolução significativa (visual, $\mathrm{t}_{9}=-5.752 ; p \leq .0001 ;$ auditiva, $\mathrm{t}_{9}=-7.339 ; p$ $\leq .0001)$.

O desempenho pelos participantes surdos nestas tarefas foi altamente correlacionado, tanto entre a tarefa visual e a auditiva, como entre pré- e pós-teste. A Tabela 1 inclui os níveis de correlação para os pares de comparações.

Uma vez que a sequência das tarefas com estruturas rítmicas monotônicas progride em complexidade, realizou-se uma análise de regressão linear para a pontuação alcançada por cada grupo em cada condição de tarefa e teste (Tabela 2). A inclinação da reta no pré-teste foi menos acentuada para o GE, enquanto que o GC mostrou uma inclinação mais acentuada. O GE aumentou ligeiramente a inclinação da reta no pós-teste, enquanto o GC manteve a inclinação constante. A maior inclinação da reta no pós-teste indica que a taxa de acerto aumentou 
Tabela 1

Niveis de correlação para os pares de comparações dos GE e GC para as duas condições, visual e auditiva, nos dois momentos de avaliação, pré- e pós-teste.

\begin{tabular}{lcccccc}
\hline & $\begin{array}{c}\text { GE pré-teste } \\
\text { auditivo }\end{array}$ & $\begin{array}{c}\text { GE pós-teste } \\
\text { visual }\end{array}$ & $\begin{array}{c}\text { GE pós-teste } \\
\text { auditivo }\end{array}$ & $\begin{array}{c}\text { GC pré-teste } \\
\text { auditivo }\end{array}$ & $\begin{array}{c}\text { GC pós-teste } \\
\text { visual }\end{array}$ & $\begin{array}{c}\text { GC pós-teste } \\
\text { auditivo }\end{array}$ \\
\hline $\begin{array}{c}\text { GE pré-teste } \\
\text { visual }\end{array}$ & $0.859^{*}$ & $0.777^{*}$ & - & - & - & - \\
\hline $\begin{array}{c}\text { GE pré-teste } \\
\text { auditivo }\end{array}$ & - & - & $0.754^{*}$ & - & - & - \\
\hline $\begin{array}{c}\text { GE pós-teste } \\
\text { visual }\end{array}$ & - & - & $0.887^{*}$ & - & - & - \\
\hline $\begin{array}{c}\text { GC pré-teste } \\
\text { visual }\end{array}$ & - & - & - & $0.932^{*}$ & $0.879^{*}$ & $0.859^{*}$ \\
\hline $\begin{array}{c}\text { GC pré-teste } \\
\text { auditivo }\end{array}$ & - & - & - & - & - & $0.849^{*}$ \\
\hline $\begin{array}{c}\text { GC pós-teste } \\
\text { visual }\end{array}$ & - & - & - & - & - & - \\
\hline
\end{tabular}

* nível de significância $p \leq .0001$

no início do contínuo, chegando a dobrar nas estruturas iniciais, tal como confirmado pelos valores do intercepto. As Figuras 3 e 4 ilustram a curva de ajuste em torno dos pontos representativos de acertos dos participantes.

O coeficiente de determinação $\left(r^{2}\right)$ indica que a variação na taxa de acerto ao longo das estruturas, entre $73 \%$ e $94 \%$, foi associada com a mudança na complexidade das estruturas rítmicas. Isto significa que a progressão na complexidade foi percebida pelos participantes resultando em proporcional redução na taxa de acertos.

Tabela 2

Parâmetros estimados na análise de regressão linear para os GE e GC nas duas condições, visual e auditiva, nos dois momentos de avaliação, pré- e pós-teste.

\begin{tabular}{ccccc}
\hline & $\mathrm{r}^{2}$ & Intercepto & $\begin{array}{c}\text { Inclinação } \\
\text { da reta }\end{array}$ & $p$ \\
\hline GE_pre_vis & 0.78 & 6.3 & -0.3 & $\leq 0.0001$ \\
GE_pre_aud & 0.86 & 5.4 & -0.3 & $\leq 0.0001$ \\
GC_pre_vis & 0.94 & 10.3 & -0.5 & $\leq 0.0001$ \\
GC_pre_aud & 0.95 & 8.2 & -0.4 & $\leq 0.0001$ \\
GE_pos_vis & 0.73 & 10.7 & -0.4 & $\leq 0.0001$ \\
GE_pos_aud & 0.83 & 10.3 & -0.5 & $\leq 0.0001$ \\
GC_pos_vis & 0.75 & 9.0 & -0.4 & $\leq 0.0001$ \\
GC_pos_aud 0.78 & 7.1 & -0.4 & $\leq 0.0001$ \\
\hline
\end{tabular}

\section{Mudanças psicomotoras influenciadas pela dança}

Antes e depois do programa de dança, os participantes surdos do GE foram avaliados em seu desempenho em provas específicas de desenvolvimento psicomotor. A Figura 5 resume as idades psicomotoras atingidas nos quatro domínios psicomotores em ambos os momentos, pré- e pós-testes.

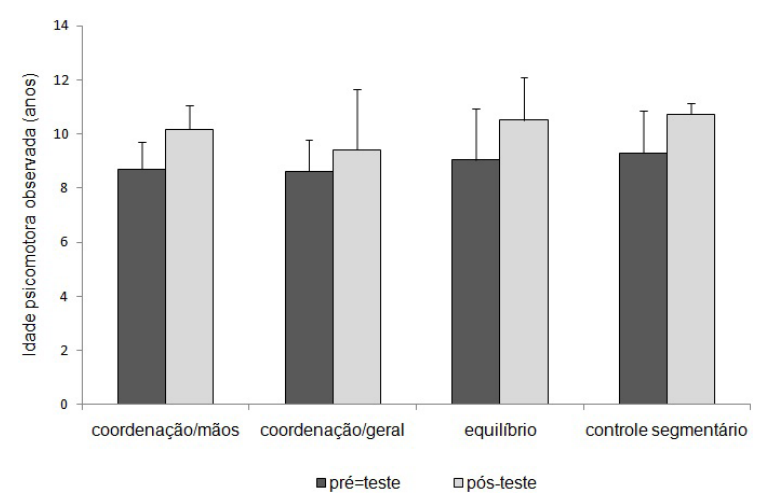

Figura 5

A variável dependente destas quatro provas foi a idade psicomotora, resultante da pontuação nestas provas do tipo "passa-falha". O desempenho inicial foi mantido entre oito e meio e nove anos. No pós-teste, as idades psicomotoras nos testes aumentaram para $10 \mathrm{e}$ 11 anos. É importante relembrar que a bateria oferece um diagnóstico até os onze anos e que a idade cronológica do grupo de surdos foi de treze anos e meio.

A idade psicomotora, parâmetro da ANOVA para dois fatores ( 2 testes $\mathrm{x} 4$ provas psicomo- 


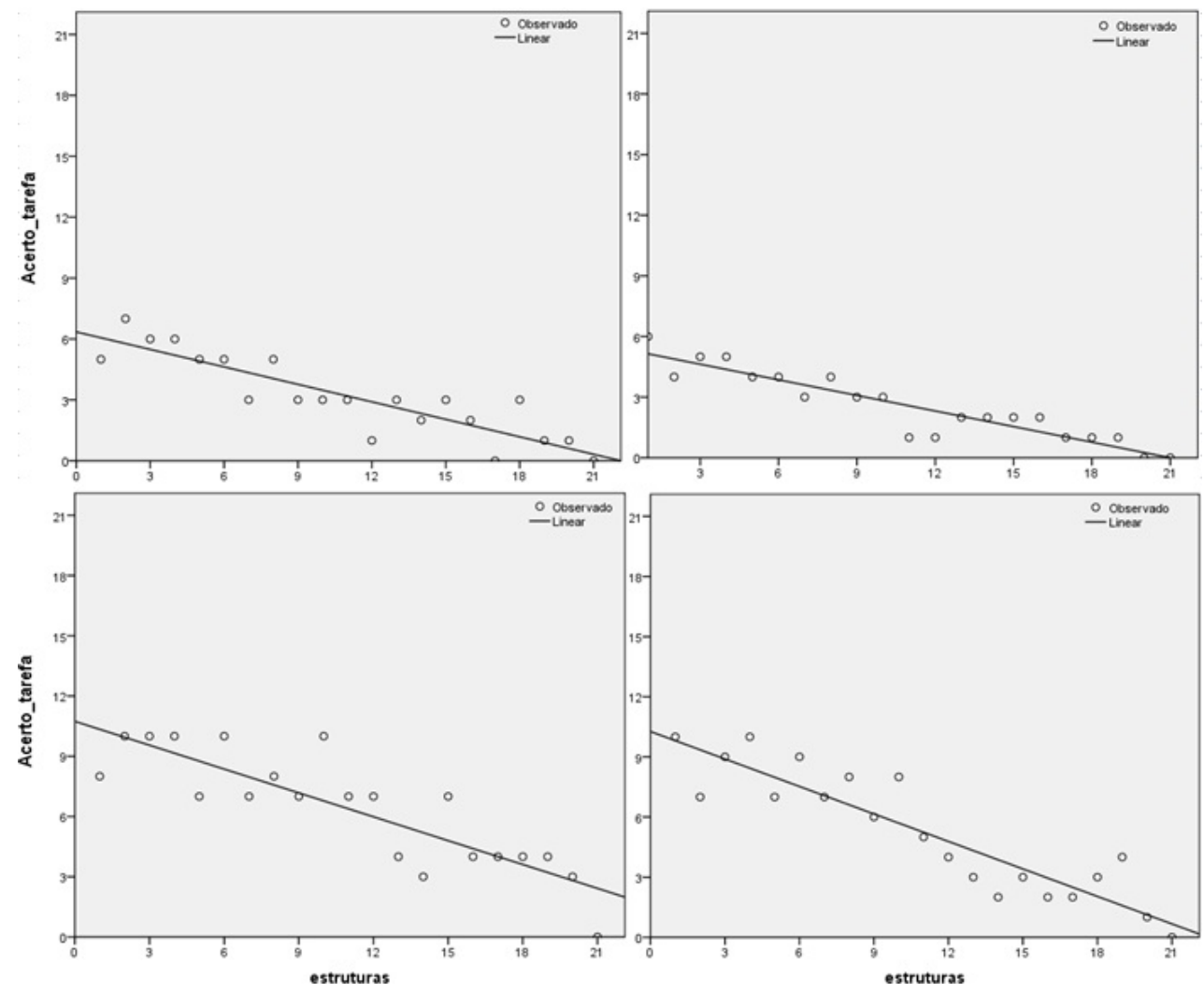

Figura 3
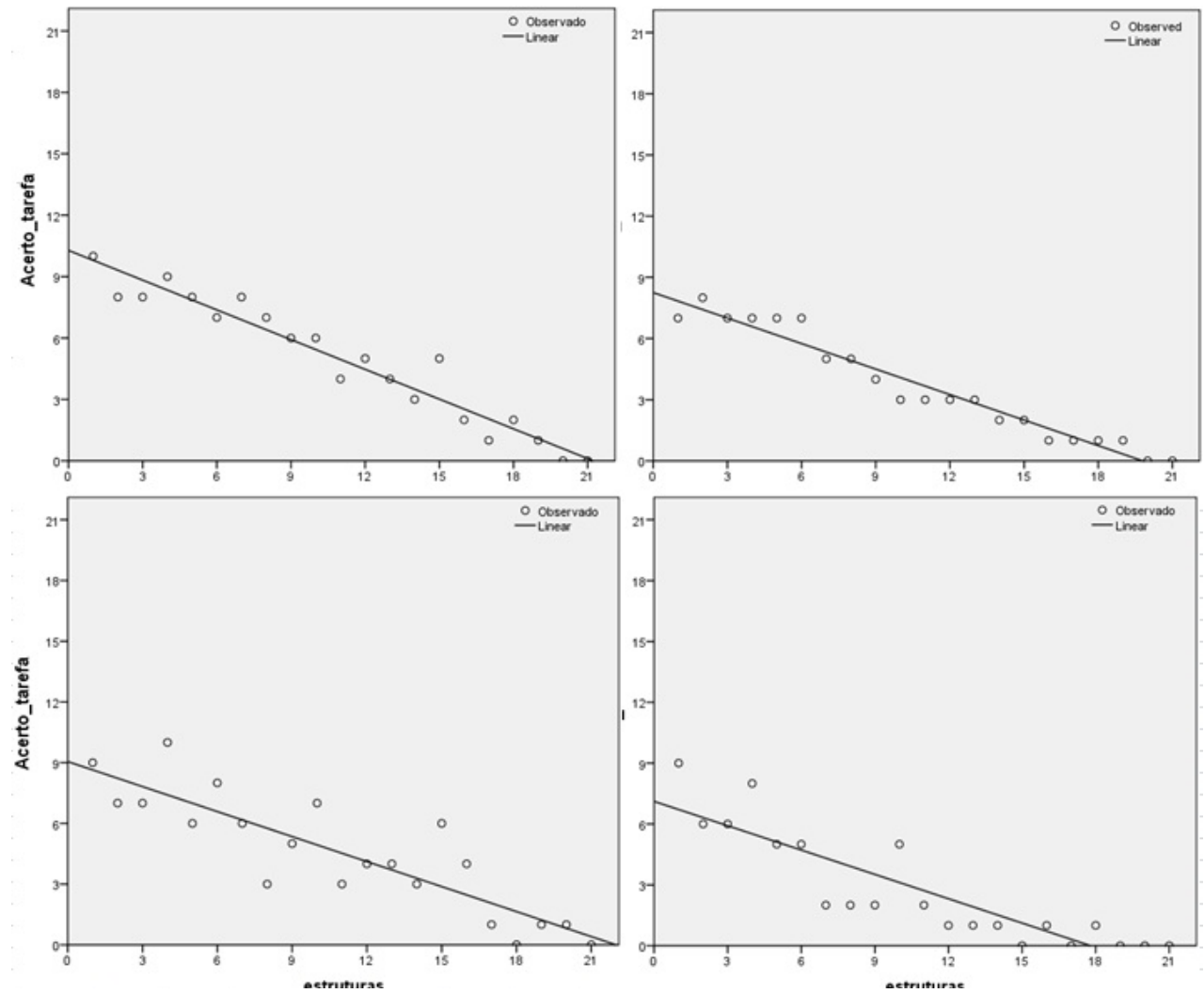

Figura 4 
toras) com medidas repetidas nos dois fatores, mostrou efeito principal para o fator teste $\left(\mathrm{F}_{1.9}\right.$ $=110.002 ; p \leq .0001 ; \eta 2=.924)$ e ausência de interação. Estes resultados indicam que o aumento na idade psicomotora entre pré- e pós-teste foi similar para todas as provas psicomotoras.

Apenas as provas de coordenação das mãos e equilíbrio mostraram alta correlação entre pré - e pós-teste, $r=.797 ; p<.006$ e $r=.746 ; p$ $<$.013. As demais comparações não revelaram nem relacionamento entre os testes, nem entre as situações de pré- e pós-teste.

A Figura 6 ilustra a magnitude na diferença entre a idade psicomotora testada e a idade computada a partir das respostas em cada prova. Em geral, o grupo reduziu a discrepância entre a idade-teste e a idade observada para menos de seis meses, após a participação no programa de dança. O maior declínio ocorreu para as provas de equilíbrio e controle segmentário. A variabilidade no pré-teste e pós-teste esteve acima de $40 \%$ para todas as observações (Figura 6). A variabilidade da diferença entre idade psicomotora teste e idade observada foi usada como parâmetro da ANOVA para dois fatores ( 2 testes $\mathrm{x} 4$ provas psicomotoras) com medidas repetidas nos dois fatores. $\mathrm{O}$ resultado mostrou efeito principal para o fator teste $\left(\mathrm{F}_{1.9}\right.$ $=28.161 ; p \leq .0001 ; \eta 2=.758)$ e nenhuma interação. Este resultado mostra que a redução da variabilidade entre pré- e pós-teste declinou proporcionalmente com a média.

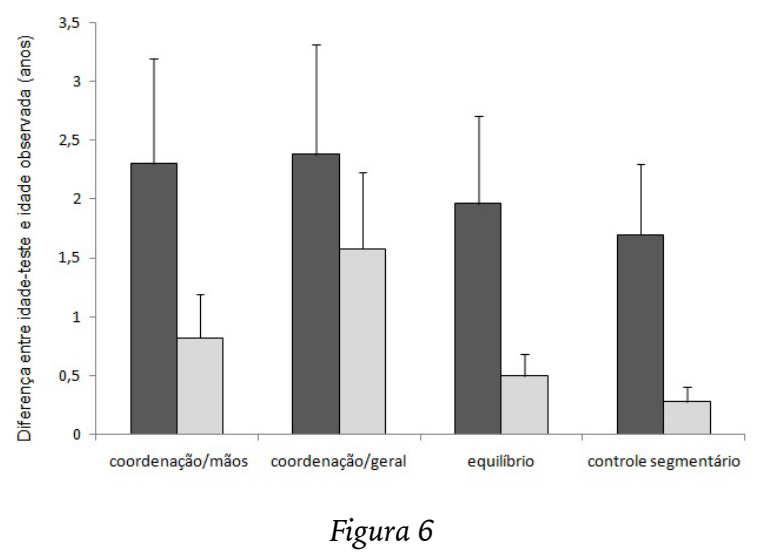

\section{DISCUSSÃO}

A participação do grupo de surdos no programa de dança resultou em uma importante e significativa melhoria na percepção das estruturas rítmicas monotônicas, tanto na tarefa com estímulos visuais como na tarefa com estímulos auditivos. Apesar do processamento das sequências monotônicas visuais ter sido superior às auditivas, o desempenho em ambas melhorou de forma proporcional após a participação no programa de dança. $\mathrm{O}$ grupo controle não mostrou alterações no desempenho após o intervalo de 26 semanas.

Lima, Pereira, e Moraes (2011), ao comparar crianças surdas e ouvintes na bateria de testes psicomotores, similar ao aqui utilizado, observaram que o desempenho das crianças ouvintes nos testes de organização temporal (os quais incluem as provas de ritmo de M. Stambak) foi melhor do que o de crianças surdas na faixa etária de seis a oito anos. Os autores deduzem que o desempenho inferior das crianças surdas pode ser reflexo de uma estimulação perceptivo-motora insuficiente na rotina escolar. A recomendação destes autores é de que programas de atividade física devam estimular o sistema postural, as habilidades motoras grossas e finas e igualmente as atividades rítmicas.

Não é surpresa que indivíduos surdos exibam melhor desempenho visual, mesmo em tarefas rítmicas como a de estruturação rítmica monotônica. Entretanto, o fato de o GE ter melhorado seu desempenho em ambas as modalidades da tarefa de estruturação rítmica monotônica indica que estratégias visuais e auditivas podem ser igualmente treinadas nos surdos. A aparente superioridade do GC em relação ao GE nas duas tarefas, visual e auditiva no pré-teste não foi estatisticamente significativa e a evolução do GE no pós-teste confirma a eficácia da estimulação inserida no programa de dança.

Ouvir é um processo de escolha onde o cérebro seleciona as informações contidas 
numa mistura de sons ambientais familiares ou não (Mauerberg-deCastro, 2011). A música e sons dentro de um programa de dança inicialmente provocam estados de ânimo positivos para o participante surdo, mas não necessariamente promovem a sua compreensão sobre o conteúdo acústico. O sincronismo rítmico do corpo em movimento com sons musicais durante uma dança depende da prática e da disponibilidade das informações visuais e auditivas. Atenção, capacidade de discriminação sonora e reconhecimento de transições coreográficas integradas à música são capacidades que devem ser treinadas num programa de dança. Esta recomendação é especialmente apropriada ao surdo. Não deve-se presumir que o dançarino surdo seja incapaz de selecionar adequadamente sons pertinentes com seu movimento corporal, porém, é pouco provável que um surdo com perda profunda identifique espectros completos de uma peça musical. No entanto, elementos sonoros de destaque (particularmente com sons graves e especialmente com instrumentos de percussão) lhe propiciam informação rítmica à qual podem ser emparelhadas dicas visuais.

O teste de ritmo de Mira Stambak foi originalmente construído para detectar problemas de dislexia em crianças na idade escolar. Aos 12 anos, crianças com desenvolvimento típico costumam cometer erros em até quatro estruturas, geralmente nas últimas sequências do teste (Zazzo, 1968). Aos seis anos, os erros chegam a 14 estruturas. Mais de $70 \%$ dos casos de crianças com distúrbios de aprendizagem investigados por Stambak (em torno de nove anos de idade) tiveram desempenho comparável às crianças de seis anos. Para os presentes participantes surdos do GE, a média no volume de erros foi de 14.3 erros no pré-teste (tarefa visual) e 14.8 (tarefa auditiva). O GC exibiu um volume médio de erros menor na tarefa visual, 10.6. Na tarefa auditiva, o volume foi semelhante ao do GE. No pós-teste, o GC manteve o mesmo volume de erros, enquanto o GE teve um volume de 7.6 erros na tarefa visual e 10 na tarefa auditiva. A possibilidade de melhoria no desempenho dos surdos neste tipo de teste confirma, de um lado, o potencial de aprendizagem em tarefas perceptivo-motoras e, de outro, o fato de que o teste não é uma assinatura de distúrbios de aprendizagem, como verificado em populações disléxicas, mas sim um meio de se avaliar o impacto da privação sensorial para certas capacidades, como o ritmo.

Foxton, Nandy, e Griffiths (2006) utilizaram tarefas com sequências tonais monotônicas e com acentos distribuídos aleatoriamente em pares de sequências com cinco notas cada. Cada sequência tinha intervalos com durações fixas (300 ou 600 ms) e com intervalos de durações variáveis que imprimiam um ritmo $(300,600$, 300 , e $600 \mathrm{~ms}$ ). Pacientes com amusia (surdez tonal causada por lesão no hemisfério direito), em comparação com um grupo controle, mostraram dificuldades em discriminar que sequência do par continha as estruturas rítmicas, ou seja, com intervalos de duração variáveis.

Apesar do senso comum de que estruturas neurossensoriais, uma vez lesadas, não podem ser substituídas ou regeneradas, existem características de plasticidade periférica em órgãos sensoriais que devem ser levadas em consideração, quando interpretando mudanças funcionais na modalidade sensorial (Robertson \& Irvine, 1989). Mesmo a tecnologia de implantes cocleares introduzida no final dos anos 80 (Harrison, Gordon, \& Mount, 2005) não garante desempenho espontâneo (i.e., reconhecimento da informação auditiva) a partir da estimulação digital dos sinais acústicos. O treino auditivo continua sendo um requerimento essencial, especialmente se um adulto surdo - que não aprendeu a falar através da escuta - escolher o implante coclear como alternativa na reabilitação periférica do órgão auditivo.

Perdas auditivas neurossensoriais raramente implicam em completo dano às estru- 
turas ciliadas do órgão de Corti. A característica anatômica deste órgão (em forma de caracol com duas voltas e meia) protege células distribuídas ao longo da membrana basilar. Células sensoriais localizadas na porção proximal do órgão de Corti são sensíveis a frequências do espectro da fala, mas também estão mais expostas a danos, tanto causados por vírus e outros teratógenos como os danos decorrentes de herança. Este prejuízo na fala ocorre por causa da especialidade de recepção das células ciliadas no órgão de Corti que se localizam no início da rampa da membrana basilar. Esta especialidade na ativação é chamada organização tonotópica (Mauerberg-deCastro, 2011), a qual reflete o mapeamento frequência específica no córtex temporal (Harrison et al., 2005).

Outro aspecto é que a extensão do dano neurossensorial pode restringir a atividade de células vizinhas no que se refere à plasticidade do sistema auditivo. Ou seja, a reorganização funcional ao nível periférico e do nervo auditivo pode ser mais limitada, se a extensão do dano for extensa, especialmente durante períodos críticos do desenvolvimento infantil (Robertson \& Irvine, 1989). Mecanismo semelhante de plasticidade é observado também para células sensoriais do sistema vestibular que foram lesadas (Hara, Takeno, Shimogori, \& Yamashita, 2005).

Frequências baixas (ou graves) são processadas em porções terminais e difusas no órgão de Corti. Assim, o treinamento auditivo ao incluir o ritmo com sons diversificados preserva o aspecto temporal do espectro acústico, independente de sua banda de frequências. Isto significa que ritmo, com eventos distribuídos temporalmente entre pulsos e pausas, é provavelmente uma característica potencialmente preservada enquanto função auditiva na condição de surdez. Assim, o ritmo pode ser considerado um fenômeno primitivo, de menor complexidade e com ativação não seletiva de células sensoriais como é o caso da discriminação de tons (ou frequência). Nesse caso, o sistema auditivo só teria que preservar uma sequência de eventos com alternância entre presença e ausência de sons. Esta sequência contém repetições de sons e suas pausas que, no caso da prova de M. Stambak, não mantém simetria (ao contrário dos ritmos musicais). No presente estudo, a percepção da simetria de ritmos musicais certamente esteve em demanda durante o treinamento com a dança e atividades rítmicas, que, por sua vez, proporcionou uma transferência para a percepção das estruturas rítmicas monotônicas no pós-teste.

A mudança no desempenho em tarefas auditivas foi demonstrada por Mauerberg-deCastro em um estudo, em 1989, com um grupo de surdos expostos a um programa de dança. Neste estudo, as tarefas auditivas compreenderam a percepção de tons apresentados aos pares, compreendendo a discriminação de tons graves e agudos. Aqui, as frequências teste foram as da banda da fala. O programa de treinamento com dança proporcionou benefícios na capacidade de discriminação tonal e discriminação de duração de tons apresentados aos pares. Os participantes aumentaram a frequência de respostas corretas de 30 para $80 \%$ nas tarefas auditivas após a participação (Mauerberg-deCastro, 1989).

No presente estudo, o treinamento auditivo foi integrado ao programa de dança de modo a refletir mudanças na capacidade de perceber, tanto visualmente, como auditivamente as estruturas rítmicas monotônicas. A melhoria no escore em ambas as tarefas indica o potencial do programa como um recurso no treino da audição, onde os surdos puderam reconhecer sons mais complexos do que a simples detecção de sinal. Além disso, o programa de dança é uma estratégia positiva para melhorar a motivação e interesse por sons de modo geral. Embora o treino auditivo para o desenvolvimento da fala fosse rotina para todos os alunos da instituição, a capacidade de percepção auditiva nem sempre era amplamente integrada à realidade da escuta dos surdos. O treinamento durante a adaptação 
a aparelhos individuais para amplificar sons é amplamente usado dentro de metodologias de ensino, tanto oralista, bilíngue, como de comunicação total. Entretanto, quando o assunto é comunicação, a tendência dos surdos é usar o recurso visual da língua de sinais, por ser a mais eficiente e naturalmente adquirida. Com o recurso de implantes cocleares e tecnologia digital de processamento de sinais dos novos aparelhos auditivos, os surdos ampliaram suas opções, inclusive no mundo dos sons. Porém, para aqueles que cresceram afastados das possibilidades de audição, a aprendizagem sobre os conteúdos acústicos, sejam eles ligados à fala, sejam à música, dependerá das oportunidades de sucesso no entendimento desses conteúdos.

\section{Influências da dança e atividades rítmicas no desenvolvimento psicomotor}

De modo geral, observou-se que o grupo que participou do programa de dança exibia atrasos psicomotores importantes antes da intervenção. Com idade cronológica média de 13 anos, o grupo exibiu uma idade psicomotora média de oito anos e meio (dois anos e meio abaixo da idade máxima da bateria, 11 anos) no pré-teste. No pós-teste, a média melhorou, mas ainda ficou seis meses abaixo da idade limite das provas de média infância. Enquanto um parâmetro diagnóstico, estes resultados acusam evidências importantes sobre a consequência da falta de oportunidades psicomotoras na rotina destes surdos. Em geral, o atraso psicomotor destes participantes revela, de um lado, falhas no desenvolvimento possivelmente de origem vestibular, e de outro, a falta de oportunidades com atividades motoras e físicas nas suas rotinas.

As provas de coordenação das mãos, por empregarem atividades de coordenação olho-mão, não deveriam representar grandes dificuldades ao grupo, uma vez que a visão e gestos são uma rotina preferencial nas atividades de comunicação pelos surdos. Porém, as provas de nove e 11 anos $^{3}$ desta modalidade compreendem precisão na pontaria e no tempo de contato, respectivamente. Estas duas provas foram aquelas com maior índice de fracasso pelo grupo. Nestas provas, o controle visual é mantido com eventos distais tanto de alvos parados, como em movimento, e que estão relativamente longe do corpo. O gesto é discreto. As demais provas são predominantemente cíclicas e os contatos com os alvos ou materiais são proximais. O controle visuomotor, neste caso, envolve apenas requerimentos posturais de estabilização do tronco.

A complexa interação entre sistemas vestibular, visual, somatossensório, e destes com estruturas centrais, como o cerebelo e hipotálamo, por exemplo, pode justificar como as limitações evoluem ao longo do desenvolvimento do sistema postural. Da mesma forma, pode explicar lacunas na coordenação visuomotora, locomoção e funções baseadas nas referências corporais e no meio externo. As pesquisas mostram que existe uma relação estreita entre perda de equilíbrio e deterioração auditiva em crianças surdas pequenas (Brunt \& Broadhead, 1982; Brunt et al., 1987; Savelsbergh \& Netelenbos, 1992). As pesquisas também mostram que o desempenho de surdos em testes de equilíbrio melhora com a idade (Butterfield \& Ersing, 1986) e com oportunidades de experiências motoras (Campos, 2003; Rine et al., 2004). Ainda não é claro, entretanto, se o desenvolvimento global de habilidades motoras, as quais dependem da aquisição postural (habilidades locomotoras, por exemplo), pode ser afetado em seus padrões ou taxas de aquisição (Mauer-

\footnotetext{
${ }^{3}$ A prova de coordenação das mãos revista para nove anos de idade requer que o participante arremesse uma bolinha de plástico de seis $\mathrm{cm}$ de diâmetro contra um alvo de $25 \times 25 \mathrm{~cm}$ localizado a um metro e meio de distância na altura do seu peito. A prova de 11 anos requer que o participante agarre esta bolinha lançada pelo experimentador a três metros de distância. O experimentador pede ao participante manter os braços ao lado do tronco e só iniciar o movimento após a instrução "pegue" que é dada no momento do lançamento.
} 
berg-deCastro, 2000).

A literatura mostra resultados que tanto confirmam como negam haver diferenças no desenvolvimento motor entre crianças surdas comparadas às ouvintes (Dummer, Haubenstricker, \& Stewart, 1996). Lima et al. (2011), utilizando a bateria de testes psicomotores (similares a deste estudo) compilada por Rosa Neto (2002), avaliaram crianças surdas e ouvintes entre seis e oito anos e observaram que ambos os grupos exibiram um desempenho similar para a motricidade fina, motricidade global e equilíbrio. Porém, na organização temporal, as crianças surdas tiveram um desempenho pior do que as crianças ouvintes. No mesmo estudo, contrário ao resultado na prova de equilíbrio de Rosa Neto, as crianças surdas tiveram maior dificuldade do que as ouvintes no equilíbrio em tarefas específicas de controle postural em posição unipodal e posição Romberg sobre superfície instável sem visão. Na bateria de Rosa Neto, a prova de equilíbrio para a idade de seis anos também é feita com os olhos fechados, porém, neste estudo, não parece ter resultado em dificuldade para o grupo surdo.

Embora a surdez não implique em atrasos motores de origem central, quando há comprometimento vestibular, o equilíbrio pode ser substancialmente comprometido, especialmente em tarefas com posições estáticas, e mais ainda quando a visão é obstruída. Um problema com as provas psicomotoras, quando aplicadas para surdos, é a adaptação com instrução e a decisão do experimentador sobre quando iniciar a observação do comportamento a partir do entendimento do participante. Isso é particularmente importante para aquelas provas que requerem o desempenho dentro de um tempo restrito.

No caso da avaliação no presente estudo, a probabilidade de perda neurossensorial associada com dano vestibular é grande, embora nenhuma avaliação clínica tenha sido realizada nestes participantes. $\mathrm{O}$ evidente atraso em várias capacidades psicomotoras ao longo das várias provas para diferentes idades da média infância pode ter sido causado pelo comprometimento vestibular. Danos no sistema vestibular nem sempre são irreversíveis, uma vez que plasticidade funcional ao nível da estrutura pode ser induzida por estimulação específica (Hara et al, 2005). Além disso, a função do equilíbrio pode ser recuperada após estimulação específica ao sistema postural, uma vez que várias estruturas tomam parte na função do equilíbrio.

A mudança no desempenho nestas provas decorrente da participação do programa de dança sugere que as atividades foram diversificadas o suficiente para provocar um impacto positivo na motricidade como um fenômeno amplo. A oferta de um programa de dança, como estruturado neste estudo, permitiu ao grupo de surdos atingir importantes ganhos funcionais, tanto na capacidade perceptiva auditiva para tarefas de estruturação rítmica, como em funções psicomotoras de forma geral. A diversidade no programa permitiu uma participação individualizada, criativa e motivadora. A dança como um instrumento a serviço da imaginação propõe oportunidades ao professor para avaliar o nível de desenvolvimento e conhecimento sobre seu aluno.

\section{CONCLUSÕES}

Um programa de intervenção com dança pode promover alterações em parâmetros de percepção auditiva utilizando tarefas com estruturas rítmicas monotônicas em surdos. $\mathrm{O}$ desempenho perceptivo visual requerido nas tarefas rítmicas foi superior ao desempenho auditivo, embora neste estudo ambas as modalidades tenham sido igualmente sensíveis às mudanças causadas pela estimulação inespecífica do programa de dança. O nível do desenvolvimento psicomotor dos surdos pode ser positivamente influenciado por um programa de dança.

"O surdo que comunica sua existência e sua 
cultura em gestos precisos, complexos, também repassa uma estética corporal universal através da dança. (...) O som e o sentido se fundem através do movimento de quem dança. A música representa um portal para a composição corporal, seja na dramatização, seja no estilo técnico coreográfico, seja na possibilidade de aprendizagem." (Mauerberg-deCastro, 2011, p. 392)

\section{Agradecimentos:}

À equipe técnica do Instituto Londrinense de Educação de Surdos e a todos os participantes surdos que aceitaram participar neste estudo. Agradecemos também à valiosa contribuição dos revisores anônimos da Revista Motricidade.

\section{Conflito de Interesses:}

Nada declarado.

\section{Financiamento:}

Nada declarado.

\section{REFERÊNCIAS}

Brunt, D., \& Broadhead, G. D. (1982). Motor proficiency traits of deaf children. Research Quarterly for Exercise and Sport, 53, 236-238.

Brunt, D., Layne, C. S., Cook, M., \& Rowe, L. (1987). Response patterns to postural perturbation in deaf children with vestibular disfunction. Journal of Human Movements Studies, 13, 1-11.

Butterfield, S. A., \& Ersing, W. F. (1986). Influence of age, sex, etiology, and hearing loss on balance performance by deaf children. Perceptual and Motor Skill, 62, 659-663.

Campos, C. (2003). Efeitos de um programa de treinamento com trampolim acrobático sobre o equilíbrio de crianças surdas. Revista da Sociedade Brasileira de Atividade Motora Adaptada, 8, 21-16.

Dummer, G. M., Haubenstricker, J. L., \& Stewart, D. A. (1996). Motor skill performances of children who are deaf. Adapted Physical Activity Quarterly, 13, 400-414.

Foxton, J. M., Nandy, R. K., \& Griffiths, T. D. (2006). Rhythm deficits in 'tone deafness'. Brain and Cognition, 62, 24-29.
Hara, H., Takeno, K., Shimogori, H., \& Yamashita, H. (2005). CGRP expression in the vestibular periphery after transient blockage of bilateral vestibular input. Otorhinolaryngology, 67, 259-265. Retrieved from http://dx.doi. org/10.1159/000089405

Harrison, R. V., Gordon, K. A., \& Mount, R. J. (2005). Is there a critical period for cochlear implantation in congenitally deaf children? Analyses of hearing and speech perception performance after implantation. Developmental Psychobiology, $46,252-261$.

Hottendorf, D., \& Gill-Doleac, S. (2005). Deaf Dancers Celebrate 50 Years of Dance! Teaching Dance to Deaf and Hard of Hearing Students: The Gallaudet University Way. Dancer Magazine, 3, 42-45.

Jarvis, J., \& Iantaffi, A. (2006). Deaf people don't dance': Challenging student teachers' perspectives of pupils and inclusion. Deafness and Education International, 8, 75-87. Retrieved from http://dx.doi.org/10.1002/dei.191.

Lima, T. C. S., Pereira, M. C. C., \& Moraes, R. (2011). Influência da surdez no desenvolvimento motor e do equilíbrio em crianças. Brazilian Journal of Motor Behavior, 6, 16-23.

Lopes, K. F., \& Araújo, P. F. (2009). Proposta de ensino de sapateado para crianças surdas. Revista Brasileira de Ciência e Movimento, 17. Recuperado de http://portalrevistas.ucb.br/index. php/RBCM/article/view/971/926.

Luiz, T. R. B., \& Araújo, P. F. (2003). Avaliação de um programa de atividade rítmica adaptada para variação dos parâmetros de velocidade do ritmo para pessoas surdas. Revista Brasileira de Ciência e Movimento, 11, 27-32.

Mauerberg-deCastro, E. (1989). Influência do treinamento sensório-motor no desenvolvimento da discriminação auditiva em indivíduos com perda auditiva neurossensorial profunda (Dissertação de Mestrado). Universidade de São Paulo: Ribeirão Preto.

Mauerberg-deCasto, E. (2000). Desenvolvimento da locomoção de crianças surdas: uma análise qualitativa do andar e do correr. Revista da Socie- 
dade Brasileira de Atividade Motora Adaptada, 5, 9-18.

Mauerberg-deCastro, E. (2011). Atividade Física Adaptada ( $2^{\text {a }}$ edição). Ribeirão Preto: Novo Conceito.

Pelc, Z. (2002). Therapeutic values of dance movement and its influence on psychomotor development of deaf persons as a form of socialization and integration with the environment. Wiad Lek, 55(Suppl), 845-849.

Picq, L., \& Vayer, P. (1985). Educação psicomotora e retardo mental. Aplicação aos diferentes tipos de inadaptação ( $4^{\mathrm{a}}$ ed.). São Paulo: Manole.

Reber, R., \& Sherrill, C. (1981). Creative thinking and dance/movement skills of hearing-impaired youth: An experimental study. American Annals of the Deaf, 126, 1004-1009.

Rine, R. M., Braswell, J., Fisher, D., Joyce, K., Kalar, K., \& Shaffer, M. (2004). Improvement of motor development and postural control following intervention in children with sensorineural hearing loss and vestibular impairment. International Journal of Pediatric Otorhinolaryngology, 68, 1141-1148.

Robertson, D., \& Irvine, D. R. F. (1989). Plasticity of frequency organization in auditory cortex of guinea pigs with partial unilateral deafness. Journal of Comparative Neurology, 282, 456-471.

Rosa Neto, F. (2002). Manual de avaliação motora. Porto Alegre: Artmed.
Savelsbergh, G. J. P., \& Netelenbos, J. B. (1992). Can the developmental lag in motor abilities of deaf children be partly attributed to localization problems? Adapted Physical Activity Quarterly, 9, 343-352.

Shahin, A. J. (2011). Neurophysiological influence of musical training on speech perception. Frontiers in Psychology, 2, 126. Recuperado de http:// www.ncbi.nlm.nih.gov/pubmed/21716639

Thalheimer, W., \& Cook, S. (2002, August). How to calculate effect sizes from published research articles: A simplified methodology. A Work-Learning Research Publication. Recuperado de http:// docs.docstoc.com/pdf/5121652/6af10ee03d03-46ac-bd77-6a17477830e7.pdf

Tsimaras, V. K., Kyriazis, D. A., Christoulas, K. I., Fotiadou, E. G., Kokaridas, D.G., \& Angelopoulou, N. A. (2010). The effect of a traditional dance training program on the physical fitness of adults with hearing loss. Journal of Strength and Conditioning Research, 24, 1052-1058.

Yuko, O., Reiki, Y., \& Kazuo, K. (1999). Dance timing for deaf person through vibrotactile stimuli: Technical report. Institute of Electronics, Information and Communication Engineers, 99, 35-42.

Zazzo, R. (1968). Manual para o exame psicológico da criança. São Paulo: Mestre Jou.

(c) EY-No Todo o conteúdo da revista Motricidade está licenciado sob a Creative Commons, exceto quando especificado em contrário e nos conteúdos retirados de outras fontes bibliográficas. 